\title{
The Confront Electrodes Faces Curvature Effect on the Electron Gun Performance
}

\author{
Muna A. Al-Khashab Abdullah E. Al-Abdullah \\ Department of Physics \\ College of Science \\ University of Mosul
}

(Received 1/ $12 / 2011$; Accepted 27/2/2012)

\begin{abstract}
A new design of electron gun has been developed to study the effect of the curvature shape of the opposite electrodes faces on its optical and operational performance. Convex and concave arc shapes of different radii and orientations of the electrodes faces combined to design a series of electron guns geometries including the flat shape of the electrode face. Each model has been studied extensively to obtain the optimum electrode curvature shape. It has been found that it is possible to improve the current density and other optical properties of the electron gun by choosing suitable arc shape and radius for the confront electrodes.
\end{abstract}

Keywords: electron gun design, electron gun performance, charged particle beam.

\section{تأنير تكهرسملوح الغلب المقلبلة عل الاء الفاف الاكتروف}

\section{الملغص}

مُ ظطوير تصميم جديد للقاف الالكتروني لغرض درلسة تأثيرشكل تكلورسطوح الأطلب المقابلة

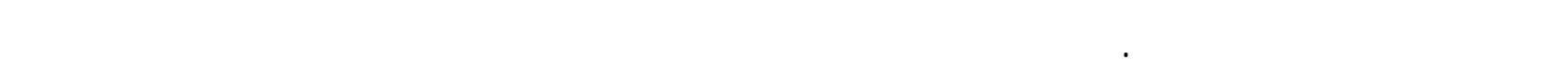

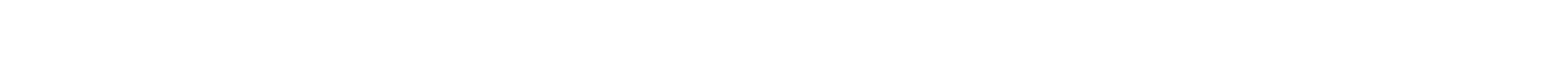

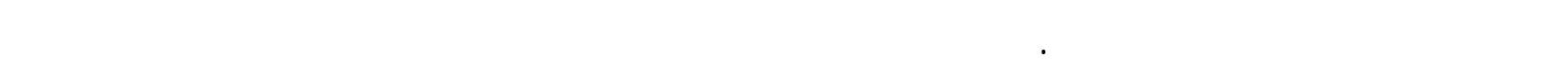
تكورسطح التطب. ووجد النه من الممكن تمسين قيم كثلفة التيار والخواص البصرية الاخرى للقاف الالكتروني من خلال لختيار مقطع دائري ذي قطر وشكل هنهسي منلبب للتطبين المقابلين.

الكاملت الدالة: تصميم قاف الكتروني، اداء القاف الالكتروني، حزمة الجسيمك المشحونة. 


\section{INTRODUCTION}

The development of the electron beam properties is of a great importance in various scientific instruments. One of the most important fields to achieve this goal is the electron emitter structure improvements.

A very sharp electron beam emitter of high brightness combined with a low accelerating voltage is required to illuminate a low voltage high resolution scanning electron microscope (HRSEM), since the fineness of the optical instrument and the aberration quantities largely depend on the electron beam properties produced from the emitter (Joy, 2010).

The high brightness with low voltage electron emitter is required in the recently developed imaging mode called "wet-STEM", and new developments in environmental scanning electron microscopy (ESEM) allow the observation of nano-objects suspended in a liquid phase, with a few nanometers resolution and a good signal to noise ratio. The idea behind this technique is simply to perform STEM-in-SEM, which is SEM in transmission mode, in an environmental SEM (Bogner et al., 2007). The superb resolution at low beam energies down to $100 \mathrm{eV}$ is achieved by employing a compound lens used recently as an objective lens in low-voltage SEM which is called "Gemini lens" (Al-Khashab and Hujazie, 2011).

In this research work the new electrodes geometries have been introduced for the electron gun, so that, the electrodes faces curvature are systematically changed to investigate the optimum shape for the confront electrodes faces. The axial potential distribution, the equipotential lines through the electrodes, the optical properties, the current densities, the brightness, the electron gun perveance and the electron probe diameter have been calculated for each electron gun geometry to choose the best design for the electrode face shape.

\section{Design Consideration}

The cross section of the prototype electron gun with its geometrical parameters is shown in Fig. (1), it is classified as triode thermionic electron gun of semi-Pierce type (Reiser, 2008). The radius of the curvature for the confront faces of the wehnelt cylinder and the anode electrodes are denoted by $r_{1}$ and $r_{2}$, respectively.

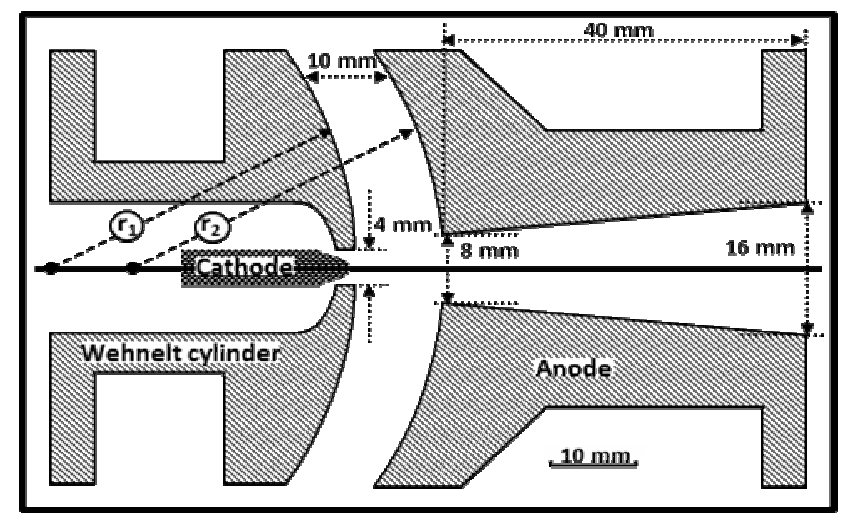

Fig. 1: Cross section of the electron gun electrodes with its geometrical parameters 


\section{PROCEDURE AND RESULTS}

In order to decide the best curvature shape geometry of the two confronts electrodes of the electron gun, a procedure has been divided into two parts:

\section{The effect of the geometrical shape on the electron gun design.}

In this part, both $r_{1}$ and $r_{2}$ are equal to $50 \mathrm{~mm}$. The general shape geometry of the electron gun is chosen according to four practically possible arrangements for the confront electrodes faces (wehnelt-anode), namely: (flat-flat), (concave-convex), (convex-concave) and (convex-convex). Accordingly, four electron gun models have been formed denoted by: EG1, EG2, EG3 and EG4 respectively, Fig. (2). All other possible arrangements may cause high-voltage breakdown due to the short distance between the guns electrodes (Stanley, 2002).

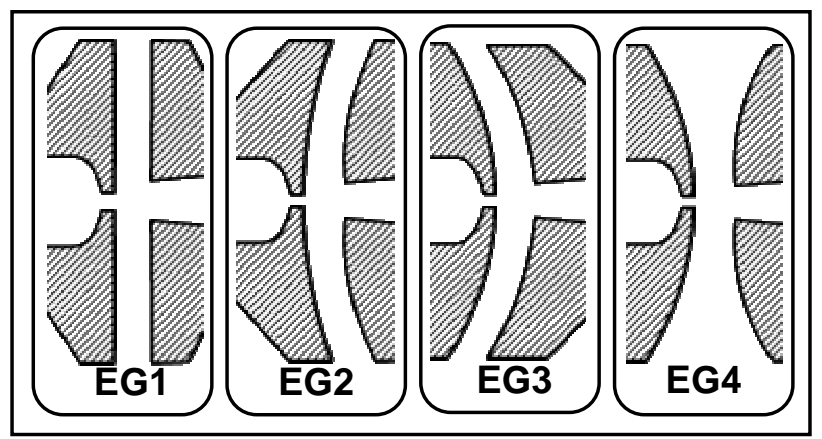

Fig. 2: The wehnelt-anode electrode face shapes of the electron guns EG1, EG2, EG3 and EG4.

The axial potential distributions, the trajectories of equipotential lines and the electron trajectories as well as the optical properties of the electron guns EG1, EG2, EG3 and EG4 are calculated at the same applied voltage of the wehnelt electrode $\left(V_{w}\right)$ and the anode electrode $\left(\mathrm{V}_{\mathrm{A}}\right)$ are equal $(-1 \mathrm{kV})$ and $(10 \mathrm{kV})$, respectively. The calculation is accomplished by using a modified version of some Munro's programs (Munro, 1975). The modification is fulfilled in this research work and included the enhancement of the fine and coarse mesh number in the axial and radial directions which provide more accurate finite element calculations, and also necessary for handling the complicated shapes design. Moreover, the programs are modified to calculate and illustrate the electron trajectories of these electron guns. The analysis is carried out by treating the triode electron guns as three-electrode immersion objective lenses (Grivet, 1972). For the above mentioned electron guns, Fig. (3) shows a comparison between the axial potential distributions. Fig. (4) shows the equipotential lines with the electron trajectories and Fig. (5) shows a comparison between the electron trajectories of the previous guns. These figures show that the electron gun EG3 has more rapid increase in the axial potential distribution and has closer crossover point to the wehnelt cylinder in comparison with the other electron gun models. 


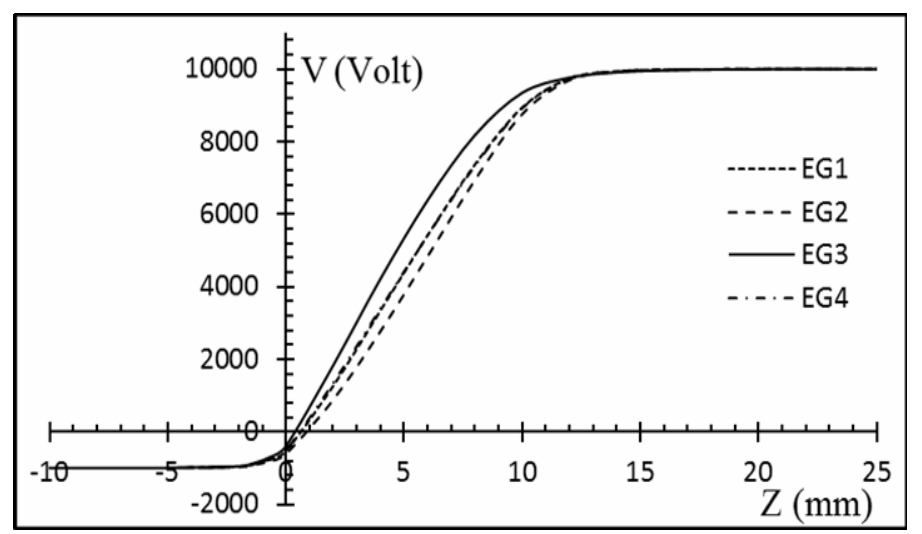

Fig. 3: Comparison between the axial potential distribution of the electron guns EG1, EG2, EG3 and EG4 calculated at $\left(\mathrm{V}_{\mathrm{w}}=-1 \mathrm{kV}\right.$ and $\left.\mathrm{V}_{\mathrm{A}}=10 \mathrm{kV}\right)$.

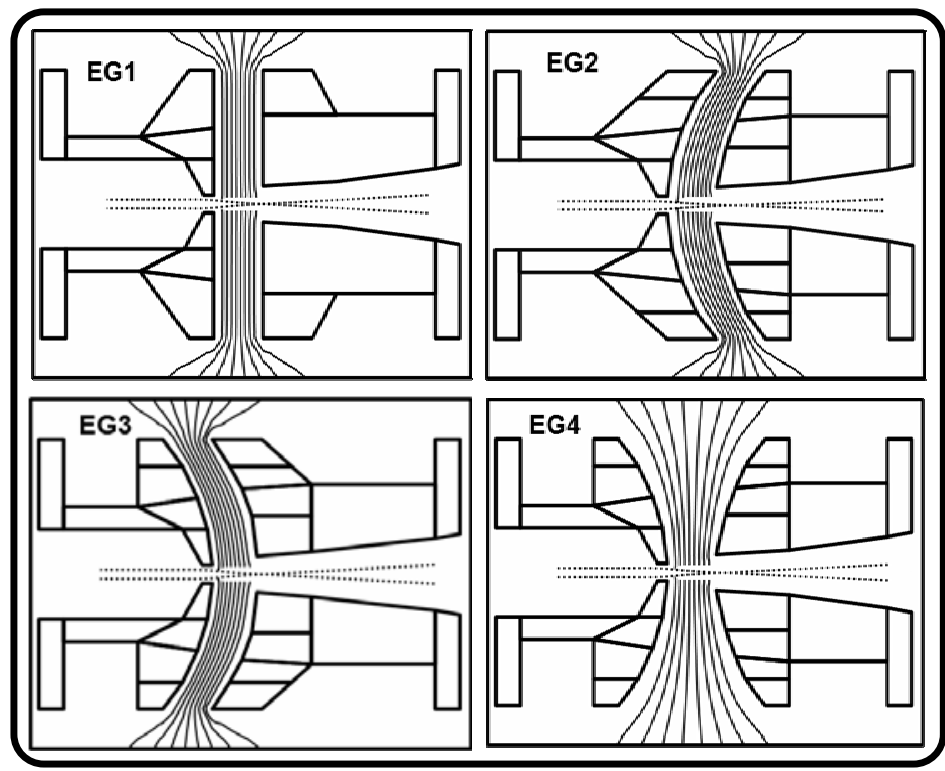

Fig. 4 : The equipotential lines (continuous lines) and the electron trajectories (dotted lines) due to the electron guns EG1, EG2, EG3 and EG4, calculated at $\mathrm{V}_{\mathrm{w}}=-1 \mathrm{kV}$ and $\mathrm{V}_{\mathrm{A}}=10 \mathrm{kV}$.

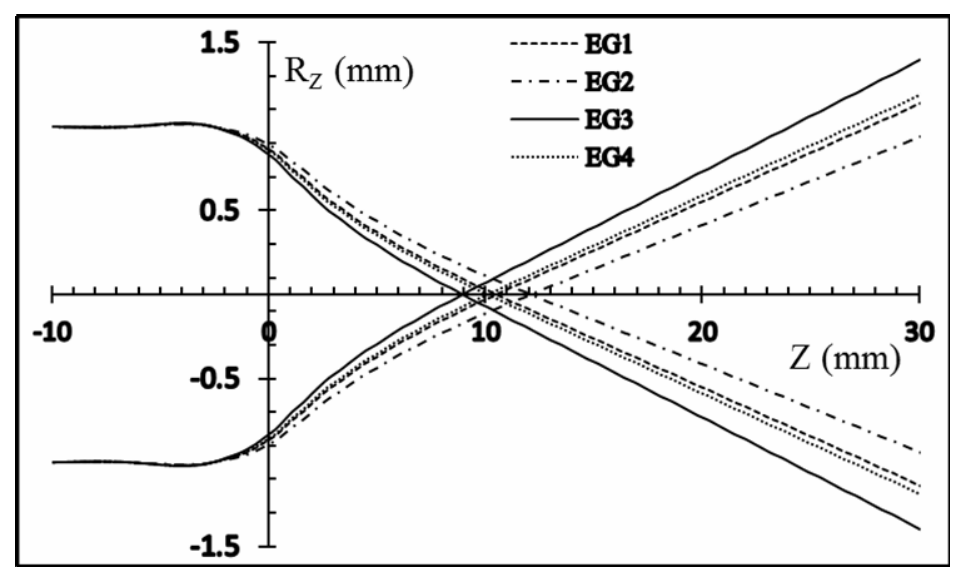

Fig. 5: Comparison between the paraxial ray trajectories $R_{z}$ of the electron beam in the electron guns EG1, EG2, EG3 and EG4, calculated at $\mathrm{V}_{\mathrm{w}}=-1 \mathrm{kV} \& \mathrm{~V}_{\mathrm{A}}=10 \mathrm{kV}$. 
The optical properties of these electron gun geometries are shown in Table (1), which represents a comparison between the image plane positions $\left(\mathrm{Z}_{\mathrm{i}}\right)$, the relative spherical aberration coefficients to the focal length $\left(\mathrm{C}_{\mathrm{s}} / \mathrm{f}\right)$ and the relative chromatic aberration coefficients to the focal length $\left(\mathrm{C}_{\mathrm{c}} / \mathrm{f}\right)$. These analyses obviously indicate that the electron gun design EG3 has acquired the best values of the optical performance than the others.

Table 1: The electron optical properties of the electron guns EG1, EG2, EG3 and EG4, calculated at $\mathrm{V}_{\mathrm{w}}=-1 \mathrm{kV}$ and $\mathrm{V}_{\mathrm{A}}=10 \mathrm{kV}$.

\begin{tabular}{|c|c|c|c|}
\hline Model & $\left.\mathbf{Z}_{\mathbf{i}} \mathbf{( m m}\right)$ & $\mathbf{C}_{\boldsymbol{s}} / \mathbf{f}$ & $\mathbf{C}_{\mathbf{c}} / \mathbf{f}$ \\
\hline EG1 & 10.49 & 6.68 & 4.75 \\
\hline EG2 & 12.08 & 7.33 & 4.76 \\
\hline EG3 & 8.94 & 5.64 & 4.67 \\
\hline EG4 & 10.10 & 6.59 & 4.76 \\
\hline
\end{tabular}

\section{The effect of the radius of curvature on the electron gun design}

This part illustrates the effect of the radius of curvature $r_{1}$ and $r_{2}$ on the electron gun EG3 (the preferable design in previous part). The values of $r_{1}$ are equal to (30, 70 and 90) mm combined with a constant value of $r_{2}$ which equals $50 \mathrm{~mm}$ to form the models of the electron guns denoted by EG5, EG6 and EG7, respectively. The value of $\mathrm{r}_{1}$ remains constant and equals $50 \mathrm{~mm}$ combined with the other values of $r_{2}$ which are equal to (30,70 and 90) $\mathrm{mm}$ to form a set of the electron guns denoted by EG8, EG9 and EG10, respectively. Finally, the values of $r_{1}$ and $r_{2}$ are both chosen to be equal to (30,70 and 90) $\mathrm{mm}$ to form the last set of electron guns denoted by EG11, EG12 and EG13, respectively.

As in the previous parts, the axial potential distribution, equipotential lines, electron trajectories as well as the optical properties of the electron guns EG5, EG6, EG7, EG8, EG9, EG10, EG11, EG12 and EG13 are calculated at the same applied voltage of the wehnelt and the anode electrodes to be equal $-1 \mathrm{kV}$ and $10 \mathrm{kV}$, respectively. Similar to part I, the calculations have been carried out by using the previously mentioned Munro's Programs. The above listed electron guns are tabled in figures to show the following: Fig. (6) shows a comparison between the axial potential distributions, Fig. (7) shows the equipotential lines with the electron trajectories and Fig. (8) shows a comparison between the electron trajectories at the cross-over points. These figures show that the electron gun model EG3 has better advantages than the other electron gun models are given above.

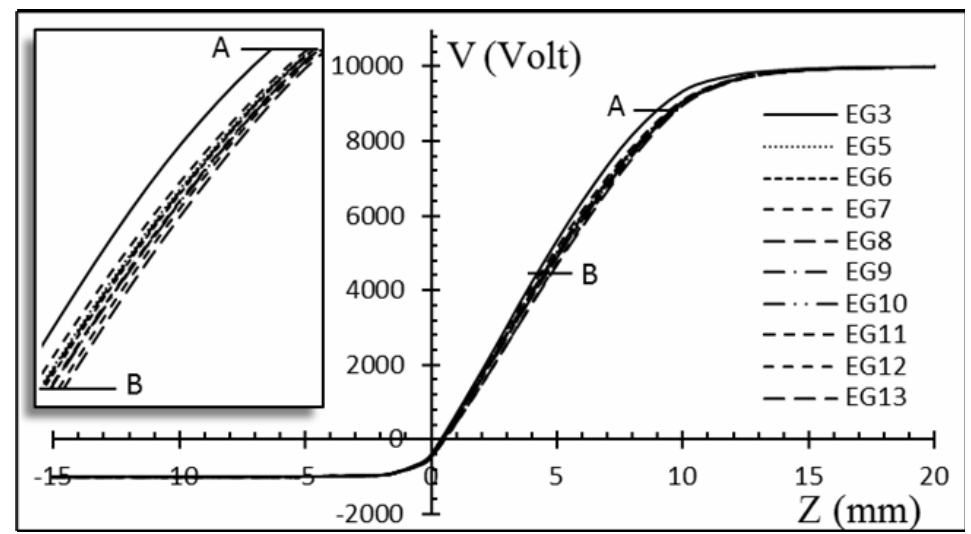

Fig. 6 : Comparison between the axial potential distribution of the electron gun EG3 with those of EG5, EG6, EG7, EG8, EG9, EG10, EG11, EG12 and EG13 calculated at $\mathrm{V}_{\mathrm{w}}=-1 \mathrm{kV}$ and $\mathrm{V}_{\mathrm{A}}=10 \mathrm{kV}$. 


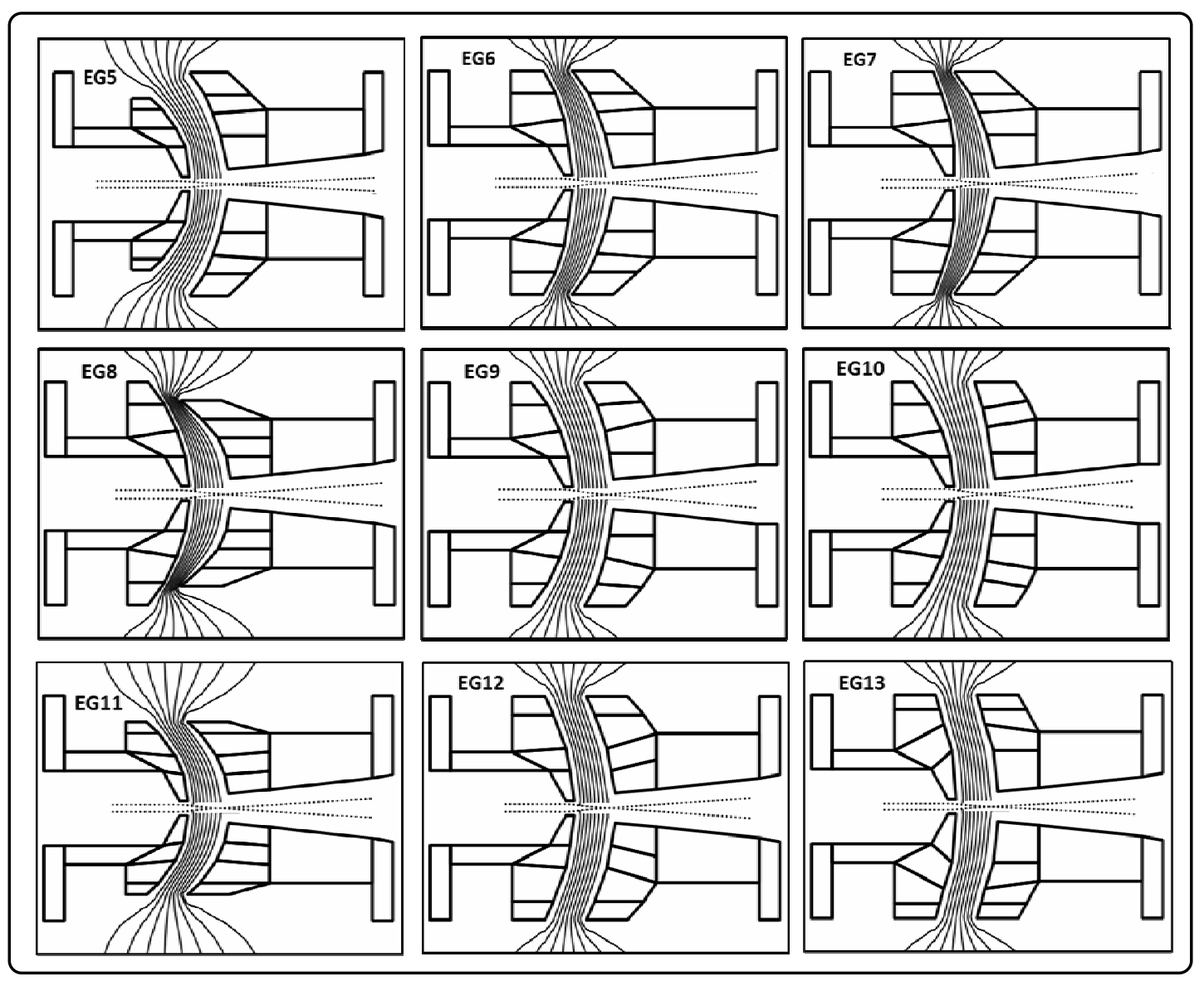

Fig. 7: The equipotential lines (continuous lines) and the electron trajectories (dotted lines) due to the electron guns EG5, EG6, EG7, EG8, EG9, EG10, EG11, EG12 and EG13, calculated at $\mathrm{V}_{\mathrm{w}}=-1 \mathrm{kV}$ and $\mathrm{V}_{\mathrm{A}}=10 \mathrm{kV}$.

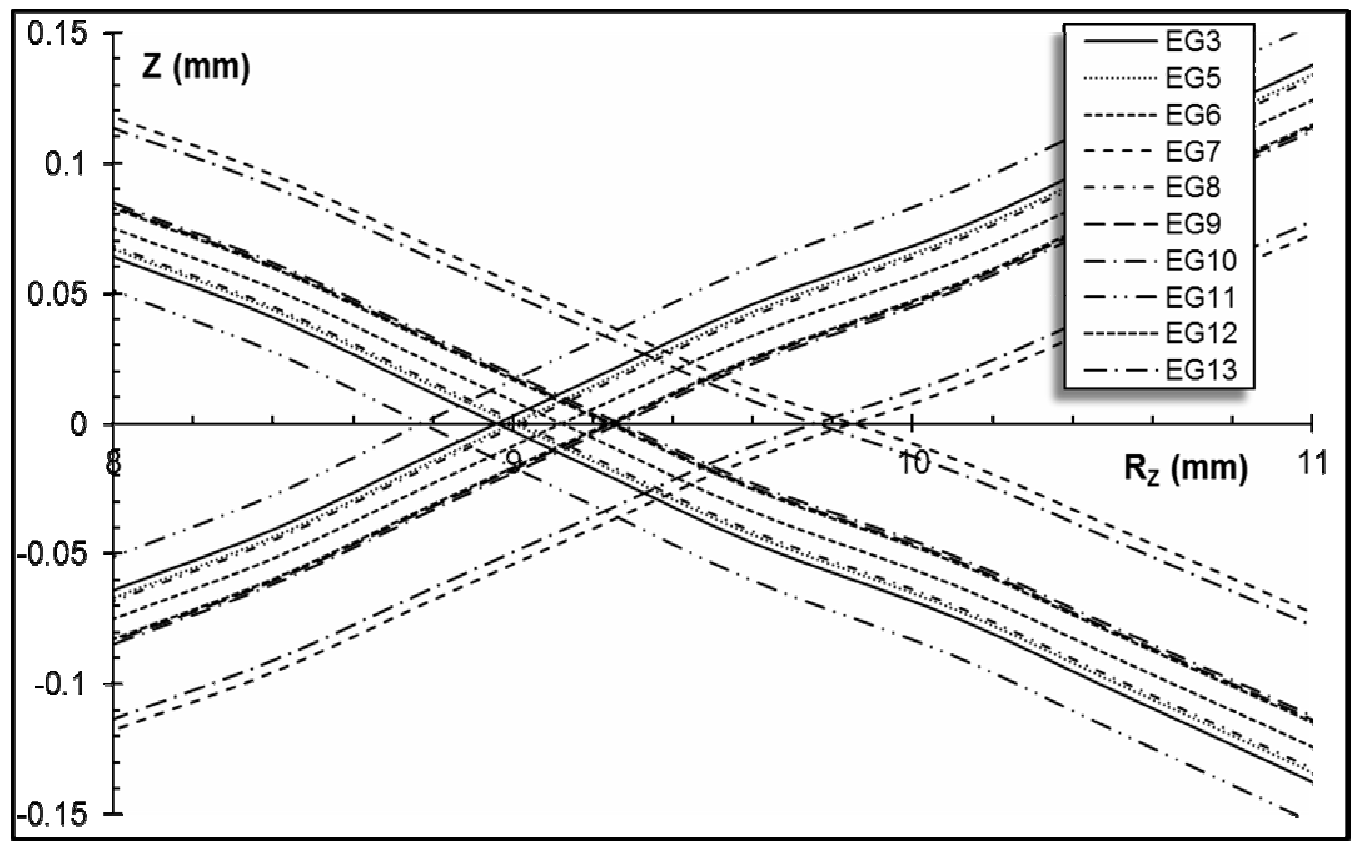

Fig. 8: The paraxial electron beam trajectories at the cross-over points of the electron models EG3, EG5, EG6, EG7, EG8, EG9, EG10, EG11, EG12 and EG13, calculated at $\mathrm{V}_{\mathrm{w}}=-1 \mathrm{kV}$ and $\mathrm{V}_{\mathrm{A}}=10 \mathrm{kV}$. 
The choice of a favorable electron gun design in an electron microscope largely depends on its focal properties. This leads to lower values of defects of the electron gun design and gives better quality image with high resolution. Fig. (9) represents the comparison of the relative spherical and chromatic aberration coefficients $\left(\mathrm{C}_{\mathrm{s}} / \mathrm{f}\right.$ and $\left.\mathrm{C}_{\mathrm{c}} / \mathrm{f}\right)$ as a function of the radius of curvature of the wehnelt face at constant radius of curvature of anode face of the previous electron guns when $r_{1}=\left(30,50,70\right.$ and 90) $\mathrm{mm}$ at constant $r_{2}=$ $50 \mathrm{~mm}$. calculated at $\left(\mathrm{V}_{\mathrm{W}}=-1 \mathrm{kV}\right.$ and $\left.\mathrm{V}_{\mathrm{A}}=10 \mathrm{kV}\right)$. This figure shows that the lower values of $\left(\mathrm{C}_{\mathrm{s}} / \mathrm{f}\right.$ and $\left.\mathrm{C}_{\mathrm{c}} / \mathrm{f}\right)$ are obtained at $\left(\mathrm{r}_{1}=\mathrm{r}_{2}=50 \mathrm{~mm}\right)$. Fig. (10) shows the comparison of $\left(\mathrm{C}_{\mathrm{s}} / \mathrm{f}\right.$ and $\left.\mathrm{C}_{\mathrm{c}} / \mathrm{f}\right)$ as a function of the radius of curvature of the anode face at constant radius of curvature of the wehnelt face of the guns when $r_{1}=50 \mathrm{~mm}$ and $r_{2}=(30,50,70$ and 90$) \mathrm{mm}$. This figure also shows that the minimum values of $\left(\mathrm{C}_{\mathrm{s}} / \mathrm{f}\right.$ and $\left.\mathrm{C}_{\mathrm{c}} / \mathrm{f}\right)$ are achieved at $\left(\mathrm{r}_{1}=\mathrm{r}_{2}=\right.$ $50 \mathrm{~mm}$ ). In addition to that Fig. (11) shows the comparison between the relative values of $\left(\mathrm{C}_{\mathrm{s}} / \mathrm{f}\right.$ and $\left.\mathrm{C}_{\mathrm{c}} / \mathrm{f}\right)$ as a function of the radius of curvature of the two electrodes faces (wehnelt and anode) when $r_{1}=r_{2}=(30,50,70$ and 90$) \mathrm{mm}$. This figure shows that the lower values of $\left(\mathrm{C}_{\mathrm{s}} / \mathrm{f}\right.$ and $\left.\mathrm{C}_{\mathrm{c}} / \mathrm{f}\right)$ occurred at $\left(\mathrm{r}_{1}=\mathrm{r}_{2}=50 \mathrm{~mm}\right)$. The above results indicated that the best optical properties acquired when the radius of curvature of the two electrodes are both equal to $50 \mathrm{~mm}$. These geometrical parameters are related to the electron gun design EG3.

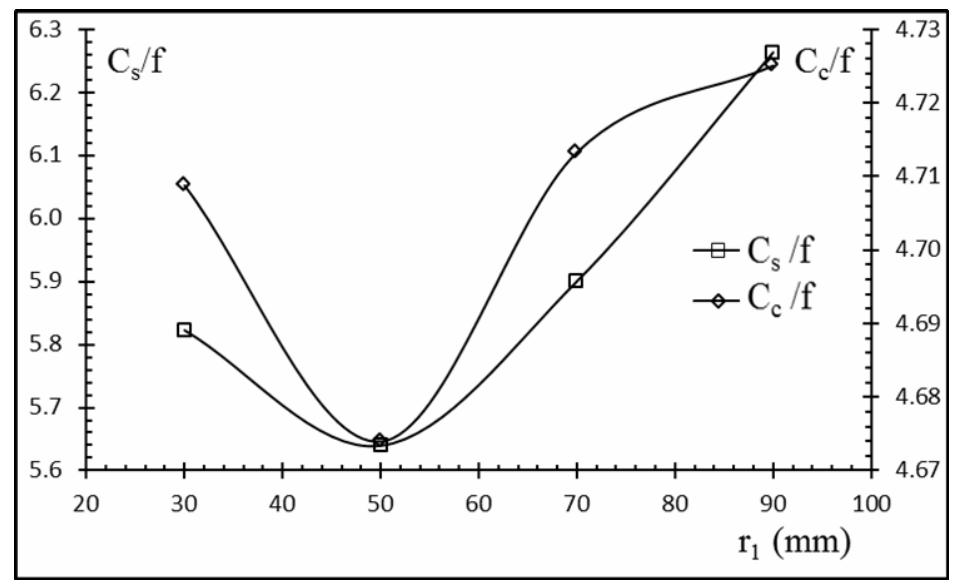

Fig. 9: Comparison of the relative spherical and chromatic aberration coefficients $\left(\mathrm{C}_{\mathrm{s}} / \mathrm{f} \&\right.$ $\mathrm{C}_{\mathrm{c}} / \mathrm{f}$ ) of the electron gun models as a function of radius of the wehnelt face curvature $\mathrm{r}_{1}$ at constant anode face curvature $\left(\mathrm{r}_{2}=50 \mathrm{~mm}\right)$, calculated at $\mathrm{V}_{\mathrm{W}}=-1 \mathrm{kV}$ and $\mathrm{V}_{\mathrm{A}}=10 \mathrm{kV}$. 


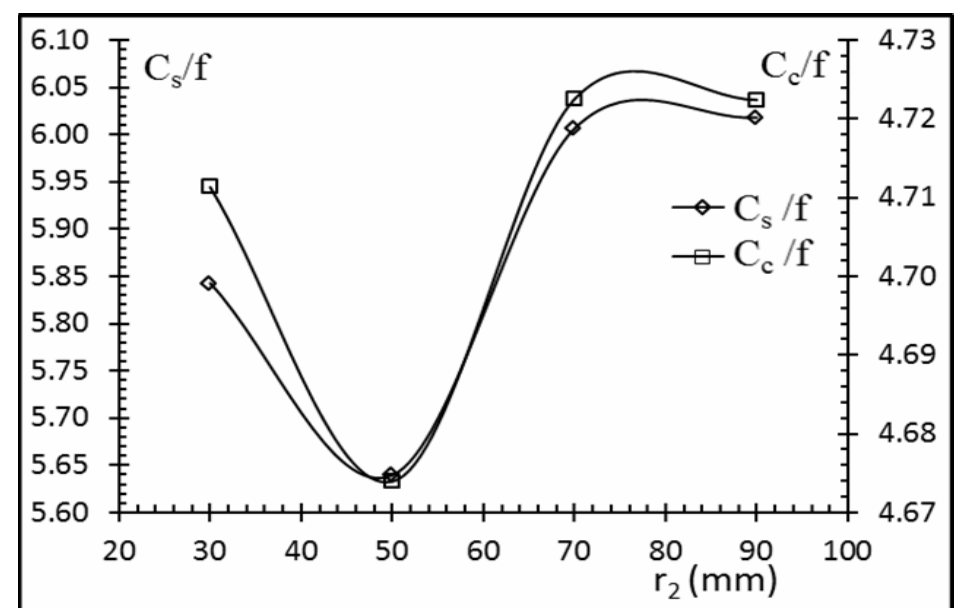

Fig. 10: Comparison of the relative spherical and chromatic aberration coefficients $\left(\mathrm{C}_{\mathrm{s}} / \mathrm{f} \&\right.$ $\mathrm{C}_{\mathrm{c}} / \mathrm{f}$ ) of the electron gun models as a function of radius of the anode face curvature $\mathrm{r}_{2}$ at constant wehnelt face curvature $\left(\mathrm{r}_{1}=50 \mathrm{~mm}\right)$, calculated at $\mathrm{V}_{\mathrm{W}}=-1 \mathrm{kV}$ and $\mathrm{V}_{\mathrm{A}}=10 \mathrm{kV}$.

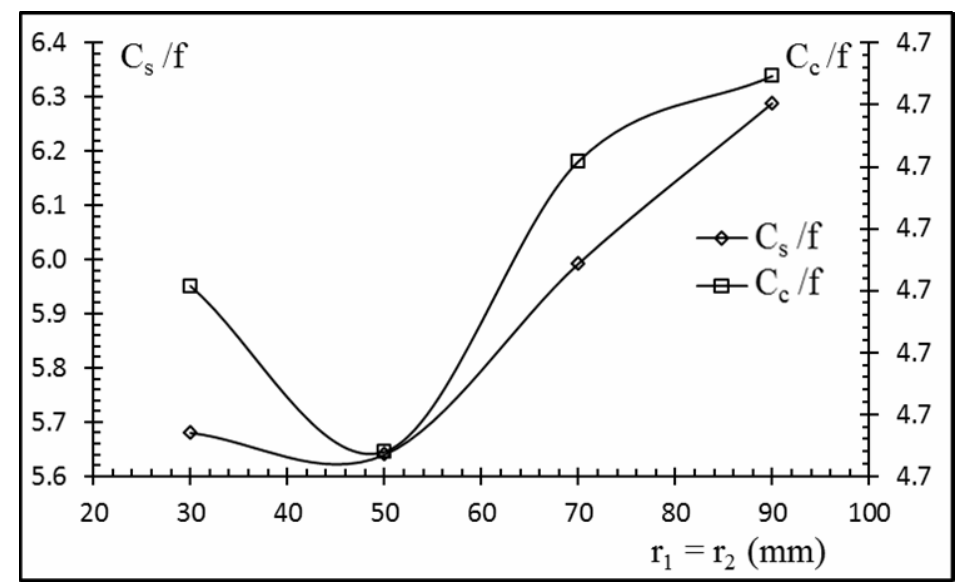

Fig. 11: Comparison of the relative spherical and chromatic aberration coefficients $\left(\mathrm{C}_{\mathrm{s}} / \mathrm{f}\right.$ $\& \mathrm{C}_{\mathrm{c}} / \mathrm{f}$ ) of the electron gun models as a function of equal values of the wehnelt and anode face curvature $\left(\mathrm{r}_{1}=\mathrm{r}_{2}\right)$, calculated at $\mathrm{V}_{\mathrm{W}}=-1 \mathrm{kV}$ and $\mathrm{V}_{\mathrm{A}}=10 \mathrm{kV}$.

Further investigations included the current density (j), the electron beam diameter (d) and the perveance $(\mathrm{P})$ are calculated for each gun design at a certain point on the optical axis ( $\mathrm{Z}=20 \mathrm{~mm}$ from the wehnelt cylinder face) at $\mathrm{V}_{\mathrm{w}}=-1 \mathrm{kV}$ and $\mathrm{V}_{\mathrm{A}}=10 \mathrm{kV}$.

The current density (j) is calculated using the following equations (Hawkes, 1996);

$$
\mathrm{j}=\Omega \beta \quad\left(\mathrm{A} / \mathrm{m}^{2}\right)
$$


where $\Omega$ is the solid angle in st. unit and $\beta$ is the maximum brightness for a thermionic gun is limited to (Hawkes, 1996):

$$
\beta=2 \times 10^{5} \mathrm{~T} \mathrm{~V}_{\mathrm{A}} \mathrm{e}^{-\varphi / \mathrm{kT}} \quad\left(\mathrm{A} / \mathrm{m}^{2} \mathrm{st} .\right)
$$

where $\mathrm{T}$ is the temperature of the filament is taken equal to $2700 \mathrm{~K}, \varphi$ is tungsten work function which equals (4.5 eV), and $\mathrm{k}$ is Boltzmann constant.

The probe diameter (d) was calculated using Peace and Nixon formula for thermionic emission filament as (Goodhew et al., 2001);

$$
\mathrm{d}=\mathrm{C} \lambda^{3 / 4} \mathrm{C}_{\mathrm{s}}{ }^{1 / 4}\left[7.92 \times 10^{9}(\mathrm{I} \mathrm{T} / \mathrm{j})+1\right]^{3 / 8}
$$

(m)

where $\mathrm{C}$ constant is about unity, $\mathrm{I}$ is the electron current and $\lambda$ is the electron wavelength given by the equation (Goodhew et al., 2001);

$$
\lambda=\left[1.5 /\left(\mathrm{V}_{\mathrm{A}}+10^{-6} \mathrm{~V}_{\mathrm{A}}^{2}\right)\right]^{1 / 2} \quad(\mathrm{~nm})
$$

The perveance is calculated using Child's law (Stanley, 2002);

$$
\mathrm{P}=\mathrm{I} / \mathrm{V}^{3 / 2} \quad\left(\mathrm{~A} / \mathrm{V}^{3 / 2}\right)
$$

The results obtained from the whole gun designs (EG1- EG13) are compared with each other as illustrated in Table (3), which shows that the perveance values are less than $10^{-8}\left(\mathrm{~A} / \mathrm{V}^{3 / 2}\right)$ in which the rule of the space charge of the electron beam is negligible and these guns are suitable for use in electron microscopes and instruments of similar nature (Grivet, 1972).

Table 2: Comparison between the current density, the electron probe diameter and the perveance of the set of electron guns EG1, EG2, EG3, EG4, EG5, EG6, EG7, EG8, EG9, EG10, EG11, EG12 and EG13, calculated at $Z=20 \mathrm{~mm}, \mathrm{~V}_{\mathrm{w}}=-1 \mathrm{kV}$ and $\mathrm{V}_{\mathrm{A}}=10 \mathrm{kV}$.

\begin{tabular}{|c|c|c|c|}
\hline Model & $\mathbf{j}\left(\mathbf{A} / \mathbf{m}^{\mathbf{2}}\right)$ & $\mathbf{d ~} \mathbf{( \mu m )}$ & $\mathbf{P}\left(\mathbf{A} / \mathbf{V}^{\mathbf{3}} \mathbf{)} \mathbf{~} \mathbf{\mathbf { 1 0 } ^ { - 9 }}\right.$ \\
\hline EG1 & 228.58 & 2.103 & 0.2189 \\
\hline EG2 & 184.38 & 1.775 & 0.0984 \\
\hline EG3 & 294.58 & 2.407 & 0.4934 \\
\hline EG4 & 242.35 & 2.190 & 0.2651 \\
\hline EG5 & 288.67 & 2.408 & 0.4703 \\
\hline EG6 & 282.92 & 2.385 & 0.4419 \\
\hline EG7 & 251.01 & 2.229 & 0.3032 \\
\hline EG8 & 289.72 & 2.411 & 0.4720 \\
\hline EG9 & 277.62 & 2.364 & 0.4154 \\
\hline EG10 & 274.64 & 2.353 & 0.4050 \\
\hline EG11 & 300.50 & 2.455 & 0.5312 \\
\hline EG12 & 277.11 & 2.362 & 0.4146 \\
\hline EG13 & 255.12 & 2.256 & 0.3182 \\
\hline
\end{tabular}


From the previous results illustrated in the tables and figures we can conclude that the models EG3 and EG11 have acquired the best electron beam properties values. However, the gun EG3 is considered the best design for the practical application.

\section{CONCLUSION}

We have shown that it is possible to improve the properties of the electron gun via improving the electrodes face geometries under the same operation condition of the applied voltage and filament temperature. A new model design of electron gun geometry with a convex wehnelt cylinder combined with a concave anode both of equal radius $(50 \mathrm{~mm})$ produce a higher current density and better optical properties in comparison with the other electron guns of different geometrical configurations of the electrode face shape.

\section{REFERENCES}

Al-Khashab, M. A. ; Hujazie, N.S. (2011). The electron optical performance of the Gemini lens design for low voltage scanning electron microscopes. Dirasat, Pure Science. 38(1), 52-60.

Bogner, A.; Jouneau, P.; Thollet, G.; Basset, D. and Gauthier, C., (2007). "A history of scanning electron microscopy developments towards 'wet-STEM' imaging", Micron 38, 390-401.

Goodhew, P.; Humphreys, J. and Beanland, R., (2001). "Electron Microscopy and Analysis", Ch5, Taylor \& Frances Inc., 137-138.

Grivet, P. (1972). "Electron Optics" . 2nd edn, part 1, Ch8, PERGAMON Press, pp. 240258.

Hawkes, P. W. ; Kasper, E. (1996). "Principles of Electron Optics". Part 2, Ch47, ACADIMIC PRESS, Inc., pp. 971-988.

Joy, D. (2010). Protons, ions, electrons and the future of the SEM. J. Phys.: Conf. Ser. 241 012002, http://iopscience.iop.org/1742-6596/241/1/012002, 1-8

Munro, E. (1975). "A Set of Computer Programs for Calculating the Properties of Electron Lenses". Cambridge University, Eng., Dept., Report CUED/B-ELECT/TR 45.

Reiser, M. (2008). "Theory and Design of Charged Particle Beams".Ch1, Second Updated and Expanded Edition, Wiley-VCH Verlag GmbH \& Co., 7

Stanley, H. J. (2002). "Charged Particle Beams". John Wiley and Sons Pub., 272 and 324. 